\title{
The effectiveness of compatible agrophytocenoses depending on the allelopathic interaction of plants
}

\author{
H.I. Semenchenko ${ }^{1 *}{ }^{*}$ A.V. Melnyk ${ }^{2}$, V.F. Zavertalyuk ${ }^{1}$, A.V. Zavertalyuk ${ }^{1}$, V.I. Pastukhov ${ }^{3}$, \\ R.V. Kyrychenko ${ }^{3}$
}
${ }^{1}$ Dnipropetrovsk Research Station of Institute of Vegetable and Melon Farming of the National Academy of Agrarian Sciences of Ukraine, Oleksandrivka village, Ukraine
${ }^{2}$ Institute of Vegetable and Melon Farming of the National Academy of Agrarian Sciences of Ukraine, Selektsiine village
${ }^{3}$ Kharkiv Petro Vasylenko National Technical University of Agriculture 44 Artema St., 61002, Kharkiv, Ukraine

Corresponding author E-mail: elen157@ukr.net

Received: 25.07.2020. Accepted: 25.08.2020

\begin{abstract}
The main criteria for the functioning of agronomic phytocoenosis are indicators of their economic and energy efficiency. In particular, the issues of manufacturability and rational use of sown areas during the growing season characterize the level of agronomic culture in a particular geographical area. Under these conditions, it is important to study the possibility of joint cultivation of agricultural plants, which will reduce energy consumption, improve the phytosanitary condition of crops and increase the profitability of agricultural production. When growing tomatoes in compatible crops, it is necessary to take into account not only aspects of technology, but also the interaction of plants with each other at the level of physiological and biochemical processes. That is why allelopathic relationship between plants, due to the physiologically active substances they secrete at the initial stage of ontogenesis, is not without the interest. It is the scientific basis for the development of sound crop rotation and mixed (compacted) crops, and also helps to increase the productivity of agro- and natural coenoses in order to prevent soil fatigue in monoculture, control weeds, pests, phytopathogenic organisms, etc. Allelopathic substances (collins) of some plant species cause different reactions to other species: some of them have active growth, others have suppressed growth processes, and still others remain neutral to such effects. The stimulating effect is manifested in the awakening of seeds, strengthening of growth processes and the formation of seedling organs. In future this fact will lead to the activation of plant development and an increase in their productivity. At the same time, mutual oppression of plants cannot be ruled out, which can be detected during laboratory studies using biological tests. Field studies of compatible (compacted) crops of tomato with other plants (sugar corn, shallots) were performed using allelopathic testing methods according to Grodzinsky. The expediency and economic efficiency of growing tomatoes in compatible crops with shallots on a green feather have been experimentally proved using statistical methods.
\end{abstract}

Keywords: Compatible crops; Tomato; Allelopathy; Shallots; Sweet corn

\section{Introduction}

These studies are aimed at developing of the elements of the tomato cultivation technology in the conditions of compaction of its crops by other crops. The advantages of compacted crops are on the following:

increasing in the output of the total production of the main crop and the compactor culture per unit of sown area; saving space on the site; increasing the duration of land use during the season (Wato T, 2020); increasing in the level of production profitability in comparison with clean crops. The determination of the most successfully combined plants for growing in compacted crops, when plants are growing together and stimulating the growth of each other, is described in the works of Grodzinsky (Grodzinsky A.M., 1970), Semenova (Semenova E.F. and et., 2011). The biological feature of tomato is that it can form high yields with minimal feeding areas without reducing the quality of products (Baleev D.N. \& Bukharov A.F., 2011). It is important to choose the right accompanying plants that would not oppress him and give high yields at the same time. The chemical interaction of plants is focused on the mechanisms of the physiological action of allelopathically active substances (collins). It is a mixture of physiologically active compounds secreted by plants or formed in their immediate environment as a result of the activity of heterotrophic organisms or physicochemical factors that effect on the surrounding plants positively or negatively (Netsere A. \& Mendesil E., 2011). The nature of the compounds included in this mixture is complex and variable. The acceptor plant perceives them together, without differentiating. And at the same time the active components in this mixture can modify (enhance or enervate) the effectiveness of physiologically active components. Therefore, the task of these field studies is to determine the total effect of the collins. Previously there was established the influence of root exudates on the process of absorption of nutrients by plants and some increases in the quality indicators of food organs (Fillipovich, 1983), (Baek, J.M., Kawecki, O.J., Ed. (2017)), a list of plants (mainly cereals) was compiled, in which there was assumed existence of allelopathic properties (Chernobryvenko, 1964), (Żurek M., Ochodzki P. \& Warzecha R., 2019). The interaction of plants is mainly carried out through the soil, since $60-90 \%$ of collins (root secretions) per unit the area is concentrated in the soil (Glubsheva T.N. \& 
Karpushina E.N., 2009). It has been proved that collins in the soil do not wash out into deeper horizons, but stay in the root layers, where you can watch the phenomenon of allelopathy (Baek J.M. and et., 2006). Therefore, it is especially important to calculate the vegetation cover in compacted crops correctly (as the beginning and basis of the functioning of the biological circulation of substances and energy) in modern vegetable growing.

\section{Material and Methods}

In laboratory conditions the biological tests were carried out on the allelopathic effect of germinating seeds of donor plants (sugar corn, shallots, beans, lettuce, dill, watermelon, melon, cabbage) on the germination of tomato seeds.

In the field conditions of the northern Steppe of Ukraine, works were carried out to study the productivity of heterogeneous tomato crops (Lagidny variety) when compaction of its crops with shallots (Dzhigit variety) and sweet corn (Delikatesnaya variety). The repetition is fourfold. The studies were carried out in the Dnepropetrovsk region, Dnepropetrovsk region of Ukraine.

The tomato was planted in the first - second decade of April, the plant density - 33-34 thousand pieces per hectare. Tomato compactors: shallots on a green feather were planted in the aisles of a tomato immediately after planting it to a depth of 4 - $5 \mathrm{~cm}$ according to the scheme $140 \times 8-10 \mathrm{~cm}$ (80 - 85 thousand pieces per hectare), sugar corn was sown in the aisles of tomatoes with a density of 14 thousand pieces per hectare. Recommended methods were used in the research (Bondarenko G.L., 2001). Research methods - measuring, visual, chemical, mathematical and statistical.

\section{Results and Discussion}

The influence of the donor plant on the acceptor plant through allelopathic interactions differs in the direction of the action (stimulating, neutral or phytotoxic) and in the degree of its manifestation (highly active, moderately active, or inactive). The carried-out studies have established that the studied donor plants, by the nature of their secretions, are inactive in relation to the germination of tomato seeds. At the same time a tendency towards their insignificant stimulation was revealed when germinating with sweet corn and shallots (Figure 1). The activity of allelopathic-active speech in bioprobes in coumarin units (UOC) for A.M. Grodzinsky is in the range of 100-105 UCO. According to the scale of NM Matveev (Matveev N.M., 1994), these plants are allelopathically inactive (0-300 UOC).

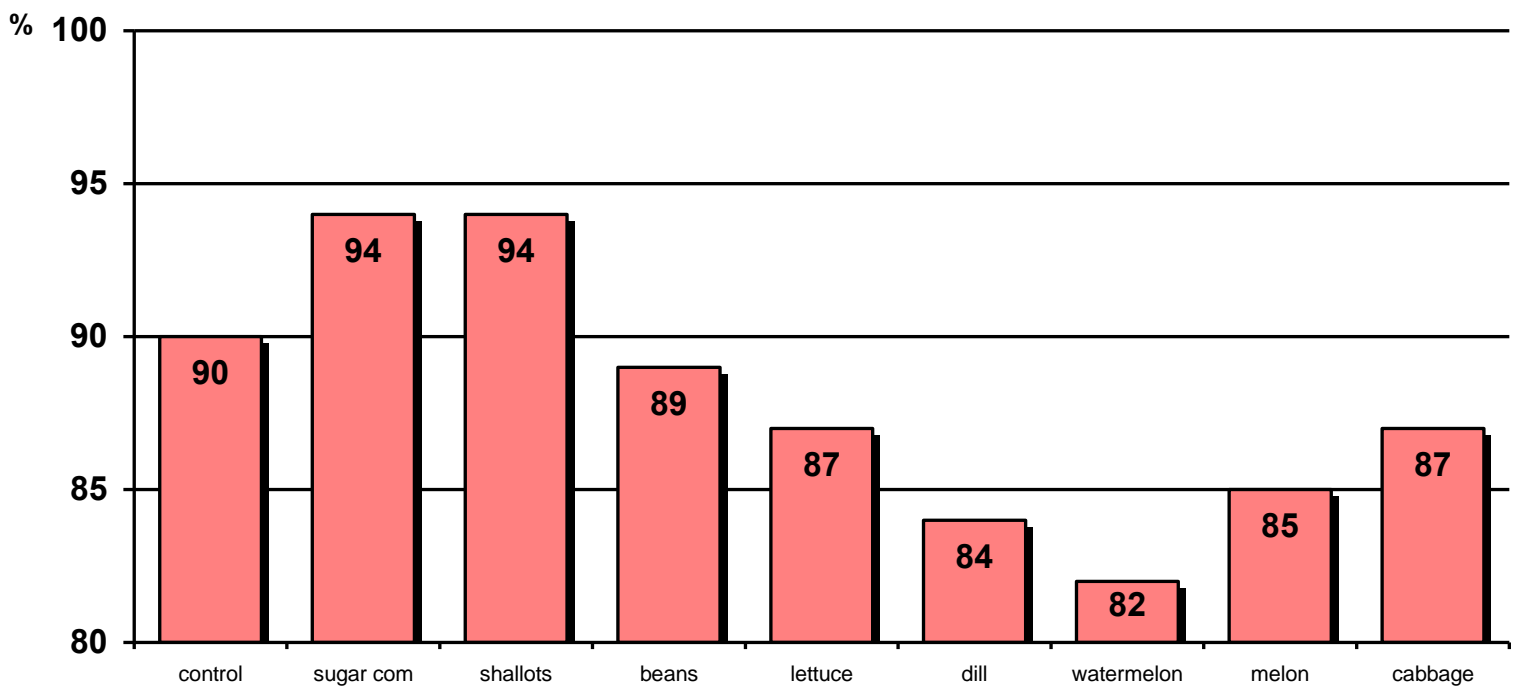

Figure 1. Germination of a tomato from allelopathic culture.

The increase in laboratory seed germination by $4 \%$ made it possible to isolate these variants for further research in the field, where the degree of allelopathic interaction of plants in joint crops is largely influenced by weather conditions and technological operations. It should be noted the stimulating allelopathic effect of tomato on germinating seeds of some accompanying crops (Figure 2). In particular, the germination capacity of sweet corn with sowing joint increased by $2 \%$, and shallots - by $12 \%$.

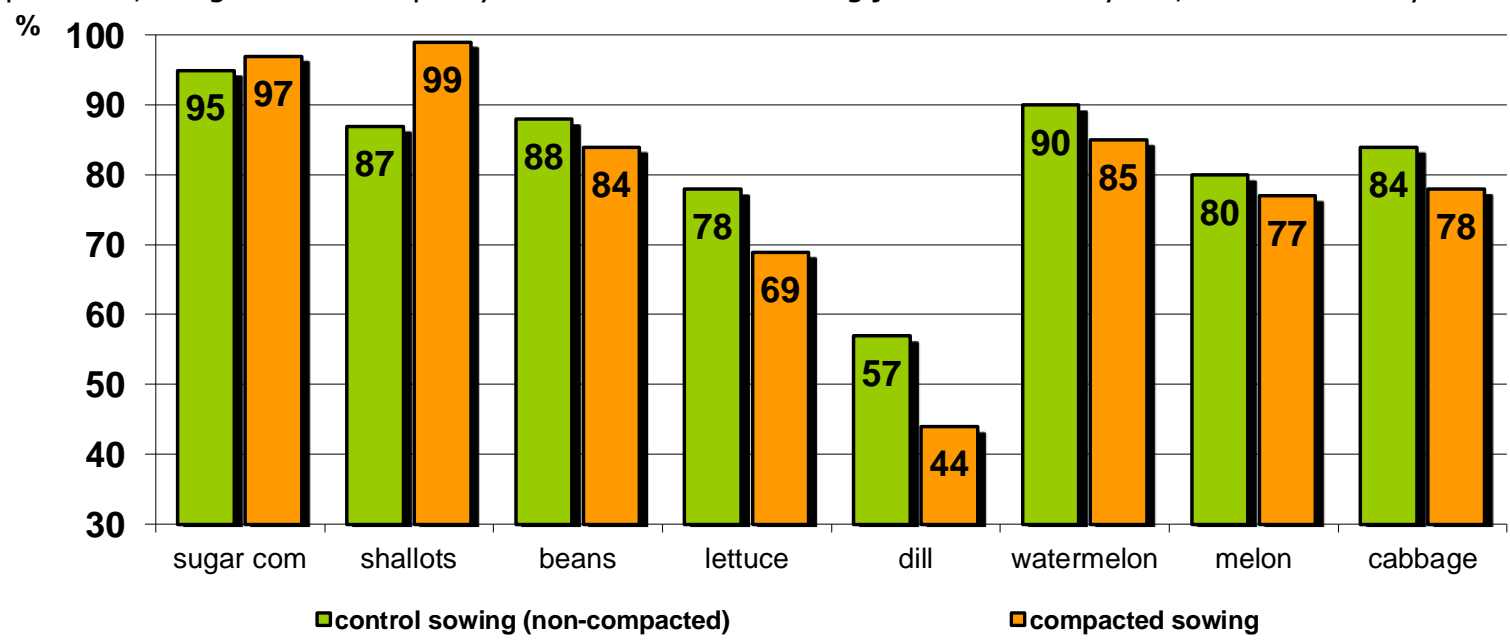

Figure 2. Germination of concomitant crops depending on the allelopathic action of tomato. 
Subsequently, this fact led to an increase in their biometric indicators and an increase in yield (Figure 3). In this case it indicates that the tomato is not only a donor plant, but also an acceptor plant, whose root secretions (collins) also have an allelopathic effect on the accompanying crops. The value of the UOC in this case was 102-114.

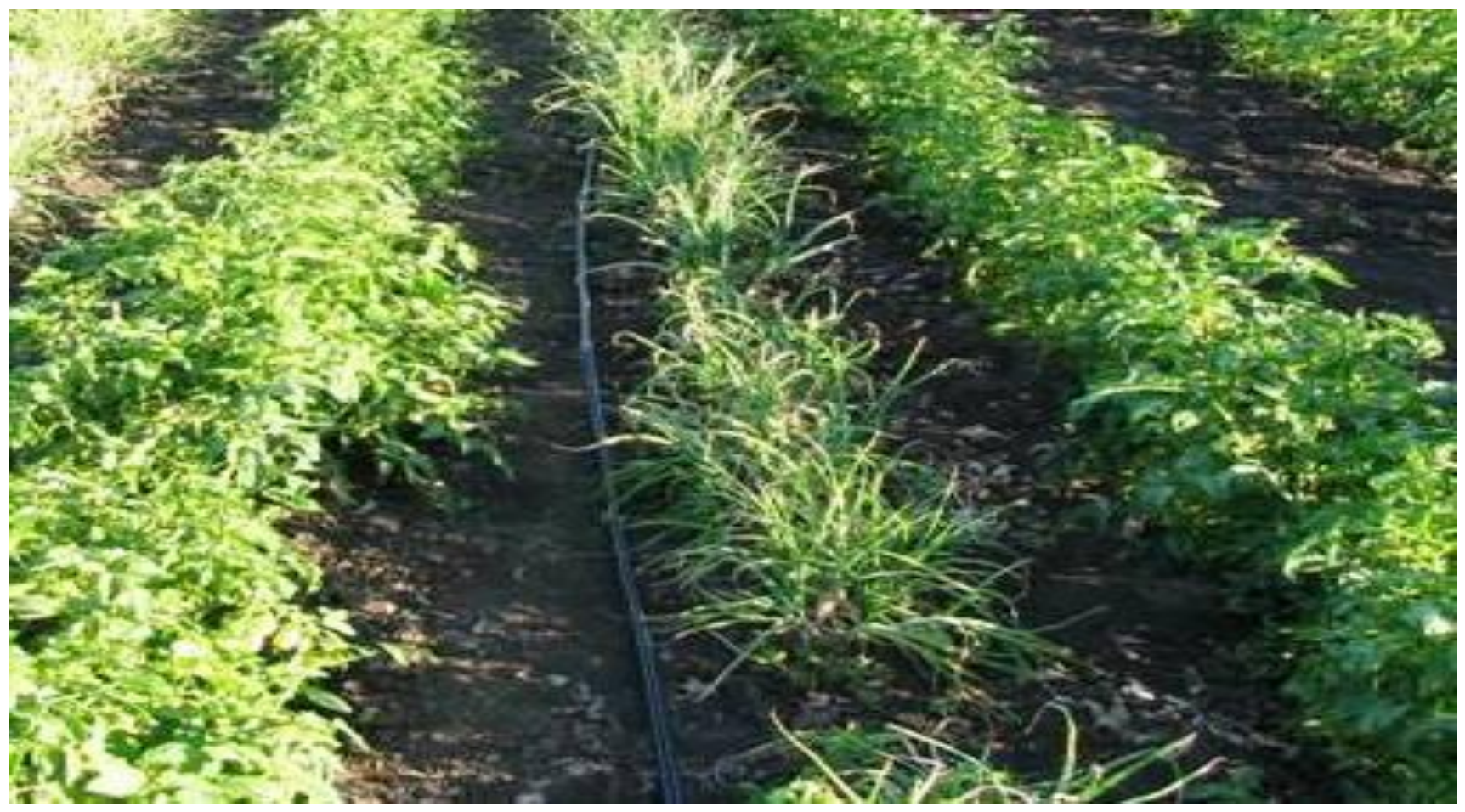

Figure 3. Compatible crops of tomato with shallots.

With the joint cultivation of tomato, a slight effect of compaction plants on its height was noted. So compacted with sweet corn, it is decreased by $2.9 \mathrm{~cm}$, with shallots - by $0.7 \mathrm{~cm}$ (Figure 4), which can be explained by the shading of plants.

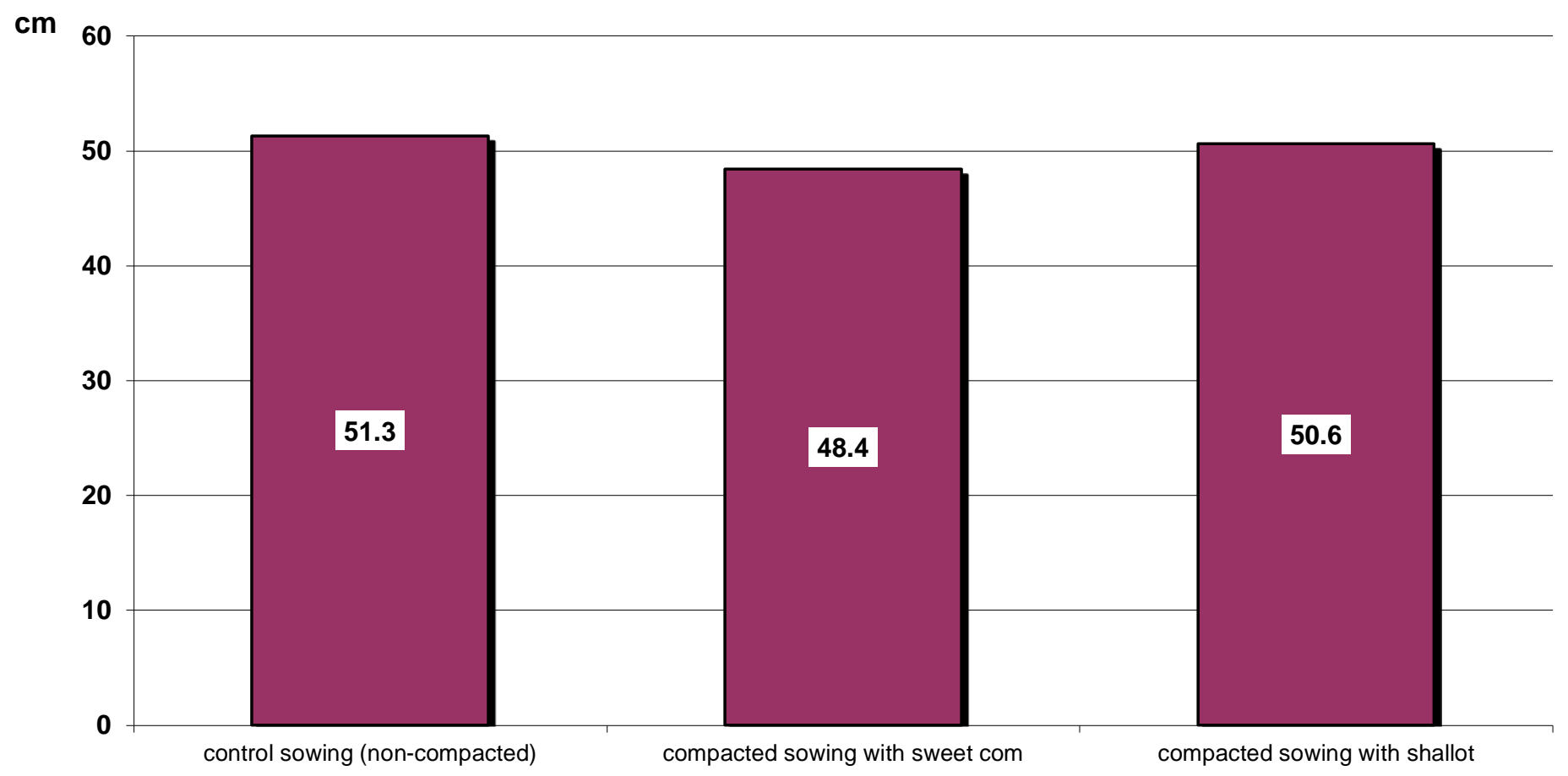

Figure 4. The height of tomato plants depends on the allelopathic action of related crops.

The yield of tomato in the control variant (sowing without accompanying crops) was $43.7 \mathrm{t} / \mathrm{ha}$, when compacted with sweet corn 42.3; shallots - $38.6 \mathrm{t} / \mathrm{ha}$. At the same time an additional yield was obtained from the same area $-4.0 \mathrm{t} / \mathrm{ha}$ of sweet corn and $6.2 \mathrm{t} / \mathrm{ha}$ of shallots, respectively (Figure 5). 
t/ha

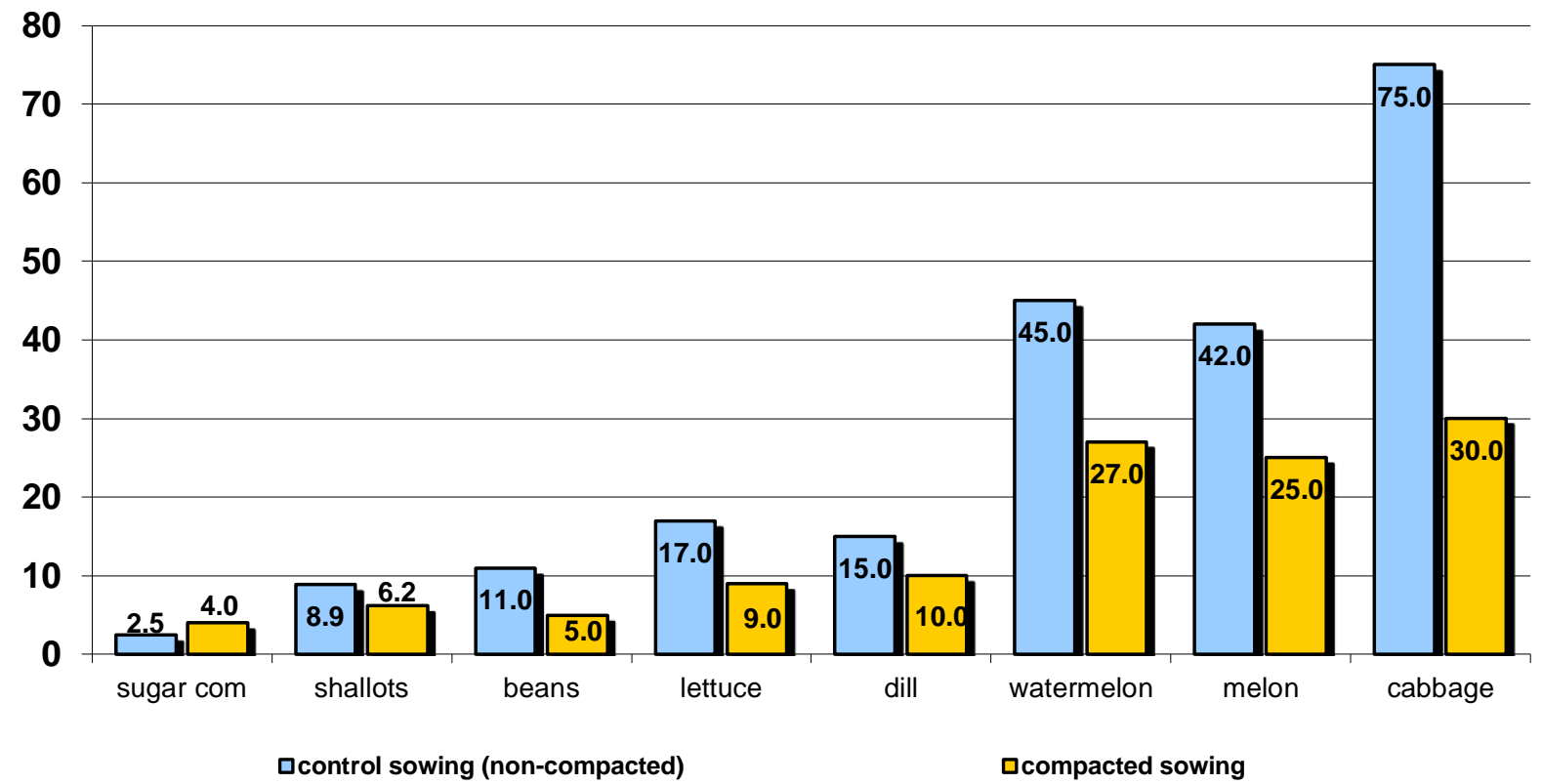

Figure 5. Productivity of accompanying crops in joint crops with tomato.

In the course of research there was established a positive effect of compaction on the carotene content: in shallots it increases to 2.5 $\mathrm{mg} / 100 \mathrm{~g}$ of raw material (with an average rate of 1.9 ), tomato - up to $1.6 \mathrm{mg} / 100 \mathrm{~g}$ of raw material (an average the norm for tomato is $1.2 \mathrm{mg} / 100 \mathrm{~g}$ of raw material). For compaction of tomatoes with shallots on green feathers the level of profitability was set at $199.8 \%$, and with sweet corn - $194.6 \%$ (control - 188.1\%).

\section{Conclusion}

In sum the results of theoretical calculations and experimental data proved the feasibility of compatible tomato crops with shallots and sweet corn due to their biochemical interaction and high economic efficiency of land use, which increases the economic effect of production by 6 times compared to pure tomato crops.

\section{References}

Wato, T. (2020). The role of allelopathy in pest management and crop production. Food Science and Quality Management, 13-21. Baleev, D. N, Bukharov, A. F. (2011). Sravneniye allelopaticheskoy aktivnosti ekstraktov iz razlichnykh organov petrushki kornevoy [Comparison of allelopathic activity of extracts from different organs of parsley

root]. Gazette of the Altai State Agrarian University. N. 5 (79), 54-56.

Grodzinsky, A.M. (1970). Problems and results of allelopathy in the works of Soviet scientists. In:Biochemical interation among plats. Washington: Nat. Acad. Sci.

Semenova, E. F., Presnyakova, E. V., Morozkina, N. A., Fadeeva, T. M. (2011). Allelopaticheskaya otsenka Ina kulturnogo Linum usitatissimyml [Allelopathic assessment of flax of cultural Linum usitatissimyml].

Maslichnyye kultury: nauchno-tekhnicheskiy byulleten Vserossiyskogo nauchno-issledovatelskogo institute maslichnykh kultur. 1, 5-11.

Netsere, A., Mendesil, E. (2011). Allelopathic effects of Parthenium hysterophorus L. aqueous extracts on soybean (Glycine max L.) and haricot bean (Phaseolus vulgaris L.) seed germination, shoot and root growth and dry matter production. Journal of Applied Botany and Food Quality. V. 84. № 2, 219-222.

Fillipovich, T.I. (1983). Seeds as allelopathic agents. In: J. Chem. Ecol.

Baek, J. M., Kawecki, O. J., (Ed.) (2017). Allelopathic effects of Nicotiana tabacum on the germination of Vinga radiate and Ttiticum aestivum. WURJ: Health and Naturae Sciences. V. 8. Issue 1, 1-5.

Chernobryvenko, S.I. (1964). «The biological role of plant excretions and interspecific relationships in mixed crops». In: Science.

Żurek, M., Ochodzki, P., Warzecha, R. (2019). Wykorzystanie właściwości allelopatycznych sorga (Sorghum bicolor) w ograniczaniu zachwaszczenia zbóż. Biuletyn Instytutu Hodowli I Aklimatyzacji Roślin. 287, 37-39.

Matveev, N. M. (1994). Allelopatiya kak faktor ekologicheskoy sredy [Allelopathy as a factor in the environment]. Samara.

Bondarenko, G., Yakovenko, K. C. (2001). Methodology of experimental work in vegetable and melon. Kharkiv: Osnova.

Dospekhov, B. A. (1985). Metodyka polevoho opyta [Field experience methodology]. Moskva.

DSTU 4138-2002. (2003). Nasinnya silskohospodarskyy kultur. Metody vyznachennya yakosti [Seeds of agricultural crops. Methods for determining quality]. Kyiv, 173.

\section{Citation:}

Semenchenko, H.I., Melnyk, A.V., Zavertalyuk, V.F., Zavertalyuk, A.V., Pastukhov, V.I., Kyrychenko, R.V. (2020). The effectiveness of compatible agrophytocenoses depending on the allelopathic interaction of plants. Ukrainian Journal of Ecology, 10(4), 56-59. 